\title{
Paraplegia
}

\section{The Quality of Life of Three Functional Spinal Cord Injury Subgroups in a Swedish Community}

\author{
A. Siösteen, BA, ${ }^{1}$ C. Lundqvist, $M D,{ }^{2}$ C. Blomstrand, $M D P h D,{ }^{2}$ L. Sullivan, \\ MD PhD, ${ }^{1}$ M. Sullivan, $\mathbf{P h D}^{3}$ \\ ${ }^{1}$ Spinal Injuries Unit, Department of Neurosurgery, ${ }^{2}$ Department of Neurology, \\ ${ }^{3}$ Departments of Medicine I and Psychology, Gothenburg University and Sahlgrenska \\ University Hospital, Gothenburg, Sweden.
}

\section{Summary}

Vast community provisions in Sweden are intended to offer spinal cord injury (SCI) subjects equal opportunities and the same living standards as the able-bodied. This study on all 56 subjects representing 3 distinct functional subgroups, out of a consecutive series treated at a Spinal Unit, explored the skills used in a wide range of community living activities and the details of these subjects' quality of life (QL). C6-tetraplegics with complete lesions $(n=15)$, wheelchair-bound paraplegics $(n=23)$ and ambulant paraplegics $(n=18)$ varied in physical independence in proportion to their disabilities but disturbances of mood states and QL perception did not differ between groups or from a control population sample. Eighty per cent of the subjects were engaged in gainful employment or education. Work/education, home management and mobility in the neighbourhood were clearly restricted by more severe disability but social and recreational activities were not. Degree of social activity and ability to drive a car were closely associated with levels of mental well-being and of perceived $Q L$. Access to transport and home-help services, appropriate housing and technical aids included few unmet subjective needs, possibly explaining why these environmental factors did not inhibit the activity levels of the study population. Extensive society support and stimulation can satisfy important needs and expectations of well-functioning SCI subjects.

Key words: Spinal cord injuries; Functional subgroups; Community living activities; Quality of life.

The spinal cord injured person is affected in several ways, both during the process of adjustment after injury and in his or her life situation following it. The limitations are both physical and psychological in nature, but some that can be improved are environmental and practical. We feel that it is timely to allow spinal 
cord injury (SCI) persons themselves describe what constitutes the limitations of their community living.

A few studies have examined the impact of physical functioning and of mental well-being on skills and activities of SCI persons' lives. Goldberg et al. (1980) found that the level of injury and the ability to perform self-care skills were related to their vocational status after discharge. MacDonald et al. (1987) reported that even mildly depressed SCI subjects were engaged in fewer self-care activities than were those who were not depressed, and that tetraplegics were overall less active than paraplegics. De Jong et al. (1984) found that marital status, education, transport barriers, economic disincentives and dependence in activities of daily living were the most important predictors of independent living.

A better knowledge of the skills and activities actually practiced by the SCI persons in their own environment would make it possible to improve the strategy to train SCI persons and to further develop their environment. However, no such comprehensive studies appear to have been presented, to date.

The primary aim of this study was thus to establish which social, recreational and vocational activities were practiced by persons with distinct SCI disabilities who lived in the community. Secondly, the self-reported physical and psychosocial function, mental well-being, sociodemographic factors and environment of these persons were to be defined and related to degrees of participation in available activities.

\section{Subjects}

This study comprises 56 SCI subjects, living in the community. There were 46 males and 10 females. To meet the primary aim of the study 3 functionally distinct subgroups were selected from an unbroken sequence of SCI subjects treated or followed-up at the Spinal Unit $(n=108)$. Further details have been given elsewhere (Lundqvist et al., 1990). Group I $(\mathbf{n}=15)$ included all C6 tetraplegic subjects with no useful motor function below the injury level. Thus, radial wrist extensors were the lowest functional muscle group, and triceps function was below fair. Group II $(n=23)$ comprised all complete or incomplete paraplegics who were dependent on using a wheelchair both indoors and outdoors and Group III $(\mathrm{n}=18)$ all ambulant paraplegics who never used a wheelchair for everyday activities. Three persons had significant comorbidity; Crohn's disease, comprehensive allergic disposition and bronchial asthma. None had suffered serious head injuries. Twelve subjects reported pain and 8 spasticity severe enough to interfere with daily function. Sociodemographic data are given in Table I. Educational level and socioeconomic class distributions did not differ from those of the Swedish population (National Bureau of Statistics; Report no. 51, 1987). Age was evenly distributed between the 3 subgroups. No significant sex difference was found in any study characteristics. In the statistical description the material was therefore considered homogeneous.

\section{National legislation and the Unit's policy for support of the disabled}

Vast community provisions in Sweden enable even severely disabled SCI persons to live independently, be mobile in their environment and earn an income. This is 
Table I Social and demographic characteristics of the study population: 56 SCI subjects.

\begin{tabular}{lr}
\hline Characteristic & $\begin{array}{c}\text { Median and range } \\
\text { or frequency }\end{array}$ \\
\hline Age & 32 yrs $18-72$ \\
Age at injury & 27 yrs $16-69$ \\
Time since injury & $2 \cdot 8$ yrs $1-22$ \\
$\begin{array}{l}\text { Living arrangements } \\
\text { alone }\end{array}$ & $20(36 \%)$ \\
with spouse & $29(52 \%)$ \\
with parents & $7(12 \%)$ \\
Pre-injury education & \\
compulsory level & $19(34 \%)$ \\
vocational school & $23(41 \%)$ \\
gymnasium & $12(21 \%)$ \\
higher level & $2(4 \%)$ \\
Pre-injury occupation & $(4 \%)$ \\
blue collar unskilled/skilled & \\
white collar assistant/professional & \\
self-employed (not professional) & \\
retired with old age pension & $(36 \%) / 17(30 \%)$ \\
\hline
\end{tabular}

prescribed by law to meet the claims of the disabled and their organisations for equal opportunities and the same living standards as the able-bodied (National Insurance Act, 1987).

The Unit's policy is to minimise a person's dependence on family members for personal care and home management. Thus, private flats or houses are rebuilt and equipped to accomodate high tetraplegics who may have day and night alarm service and regular home help and care. No subject in the present consecutive series $(n=108)$ was placed in an institution.

All who can learn to drive an individually handicap-adapted car are encouraged to do so. Significant costs for the car, its climate adjustment and the driving lessons are defrayed by various benefits but maintenance and fuel are not. Supplementary local and regional taxi service and national flight service are provided for all who cannot use public transport, with minimum outlay for the subjects. Nearly half of all income of the taxi business in the city of Gothenburg comes from subsidies for transport of the disabled (Auditors' report, 1987).

On the labour market employers are obliged to offer employees who become disabled after injury alternative jobs that they can manage, if such jobs exist, or are feasible to create. The state provides a stimulation benefit to employers as part of the disabled person's salary and all reeducation and adaptation of the work place is free of charge. Our Unit's policy is that all should be urged to return to a job specified in advance so that the education and training can be tailored for it. Training without predetermined placement is avoided and no subjects are sent to sheltered workshops if they do not have a brain injury or are mentally afflicted. Private insurance income is heavily taxed and supplementary means from disability pension insurance are usually restricted until the subject has failed repeatedly in vocational education or work. The national unemployment rate is 2 to $3 \%$.

The social service system is expensive for the society. The community tax alone takes $30 \%$ of all income. Maximal tax level in 1987 was $75 \%$ and was reached at income levels over $£ 20000$ a year. 


\section{Methods}

\section{Procedure}

The subjects were examined at the Unit, according to a fixed schedule. A clinical examination was performed by 2 neurologists independently. The physical, social and psychological characteristics and the various activities dealt with in this study were recorded using generic and specific questionnaires.

\section{Measurements}

Well defined activities were graded to define the current life situation of SCI persons living in the community (dependent variables). They are listed in Table IV and, where appropriate, scale range of category scores is given. Careful psychometric procedures were used to develop questions and scores in order to strengthen reliability (Nunnally, 1978).

The subjects' involvement in work or studies and their level of contentment were recorded. Private transport was defined as a person's ability to drive a car and to manage transfers independently. Performance of home-making tasks, e.g. cooking, washing and cleaning etc and the degree of assistance needed (3-point scale) were measured. Subjects' mobility in the neighbourhood included their engagement in shopping, banking etc. Level of participation in physical training and sports (recreational or competitive) and any reason for not participating were recorded. Taking part in given social activities e.g. cinema, restaurant, visiting friends over the past month was noted. The subjects characterised types and frequencies of their hobbies and interests and reported any pre-injury interest adapted to the disability and all new leisure activities.

Physical, psychological, environmental and sociodemographic factors (independent variables) were hypothesised to influence the above activity patterns. Definition of concepts and measurements used are given in Table II. The severity of disability, i.e. subjects' assignment to the 3 subgroups is treated as an independent variable in the analysis (Table VI).

\section{Statistical methods}

Pitman's non-parametric permutation test was used for the significance testing of relationships between severity of disability (C6 tetraplegics, wheelchair-dependent paraplegics, ambulant paraplegics) and areas of activity (Table IV), functional and emotional status and quality of life (Table III) (Bradley, 1968). The $1 \%$ significance level was chosen. Partial correlations were performed according to a non-parametric analysis (Mantel's test; Mantel, 1963) to detect the strongest predictors of well-defined activity areas. A multiple correlation procedure was used to describe the level of explained total variance. Pearson's correlation coefficient was used for description of level of correlation (Table VI).

\section{Results}

The functional and emotional status of C6 tetraplegics, wheelchair-dependent 
Table II Physical, psychological, environmental and sociodemographic measures.

Definition of concepts
Overall function:
Physical, psychological and
social impact of disability

Physical function:

Limitations in performance of body care and movement, mobility, ambulation

Usual performance of feeding washing, dressing, bathing, bladder and bowel care, wheelchair transfers

Personal assistance

Proficiency in

wheelchair driving/ambulation; indoors, outdoors, rough surface, heavy doors, curbs, up and downstairs

\author{
Psychological function \\ Perceived disorders of \\ emotional behavior, \\ social interaction, \\ altertness behavior, \\ communication \\ Perceived mood disturbances \\ pleasantness-unpleasantness \\ activation-deactivation \\ calmness-tension \\ Feelings of \\ anxiety \\ depression
}

Quality of Life (QL):

Self-perceived overall QL

Accessibility of the environment: Social services received with home-help, adaptation of home, workplace, transport, technical aids Contentment with provided services/equipment

Sociodemographic data:

Sex, age, age at injury, time since injury, educational level, living arrangements
I get dressed only with someone's help

Do you need assistance with bladder care?

Do you get assistance from homehelps or relatives?

Can you manage curbs in your wheelchair

I am going out less to visit people

In high spirits--depressed Attentive-unenterprising Relaxed-tense

I can sit and feel relaxed

I have lost interest in my appearance

How would you rate your quality of life these days?

Do you have transport service for the disabled?

Is your need of home-help service met?
Measure

Sickness Impact Profile

Overall SIP. 136 items

Generic measure

Bergner et al. (1981)

Sickness Impact Profile

Physical dimension.

45 items. Generic measure

Bergner et al. (1981)

Self-care and mobility index. 21 items.

Cronbach's alpha 0.79

SCI specific measure

Sickness Impact Profile

Psychosocial dimension

48 items. Generic measure

Bergner et al (1981)

Mood Adjective Check List

(MACL). 38 items

Generic measure

Sjöberg et al (1979)

Hospital Anxiety and

Depression scale (HAD)

16 items. Generic measure

Zigmond and Snaith (1983)

Visual Analogue Scale (VAS)

Generic measure

McDowell and Newell (1987)

18 items

SCI specific measure 
Table III Functional and emotional status and quality of life ratings in three subgroups of SCI subjects $(\mathbf{n}=56)$. Relationships of severity of disability (C6 tetraplegics, wheelchair-dependent paraplegics, ambulant paraplegics) to each health status measure.

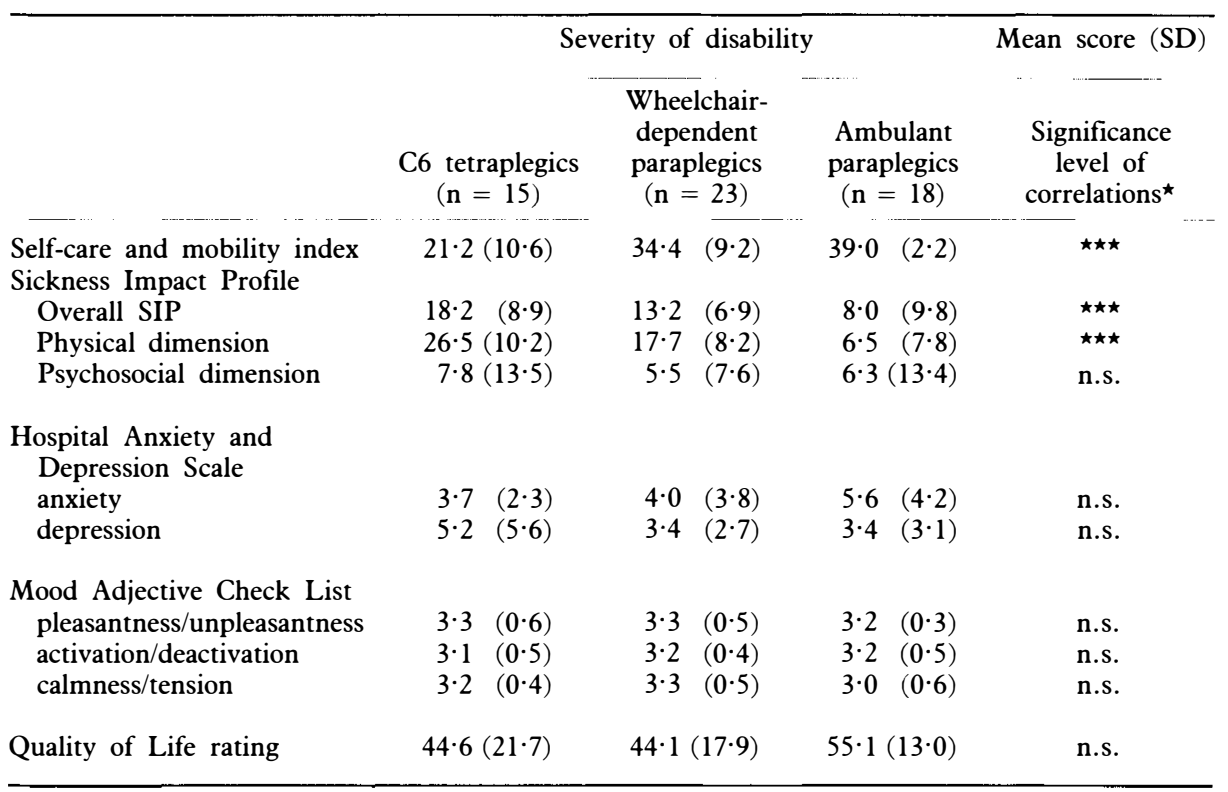

Self-care and mobility index; range of score $0-42$.

Sickness Impact Profile; range of dysfunction score $0-100$.

The Hospital Anxiety and Depression Scale; range of score 0-21.

Mood Adjective Check List; range of well-being score 1-4.

Quality of Life rating; range of score 10-70.

$\star$ Pitman's permutation test.

$\star \star \star \mathrm{p}<0.001$.

n.s. $=$ nonsignificant.

paraplegics and ambulant paraplegics are shown in Table III. The level of dependence in self-care tasks and proficiency in wheelchair ambulation skills varied greatly both within and between the 3 groups of subjects. In contrast, no correlation of severity of disability was found concerning level of depression, state of mood, and overall quality of life (QL). Physical dysfunction scores but not psychosocial and mental ratings differed from a control population sample (Lundqvist et al., 1990), (not shown in the Table).

Activity scores of the 3 subgroups are presented in Table IV. Work/education, home-making and mobility in the neighbourhood were activities clearly restricted by more severe disability (C6 tetraplegics vs wheelchair-dependent paraplegics vs ambulant paraplegics). Independence in private transport i.e. car transfer, driving and management of the wheelchair, when needed, did not correlate with severity of of disability, neither did social and other leisure activities.

As shown in Table $\mathrm{V}$, the majority of the subjects were content with the arrangements made to improve the access to their home, place of work and transport. In addition, very few subjects (7\%) reported unmet needs of home help service or technical aids.

Relationships of the various activities to physical, psychological and sociodemo- 
Table IV Activity patterns in three subgroups of SCI subjects $(\mathbf{n}=56)$. Relationships of severity of disability (C6 tetraplegics, wheelchair-dependent paraplegics, ambulant paraplegics) to each activity area.

\begin{tabular}{|c|c|c|c|c|}
\hline & & ity of disability & & Mean score (SD) \\
\hline & $\begin{array}{l}\text { C6 tetraplegics } \\
(\mathbf{n}=15)\end{array}$ & $\begin{array}{l}\text { Wheelchair- } \\
\text { dependent } \\
\text { paraplegics } \\
(\mathbf{n}=23)\end{array}$ & $\begin{array}{l}\text { Ambulant } \\
\text { paraplegics } \\
(\mathbf{n}=18)\end{array}$ & $\begin{array}{l}\text { Significance } \\
\text { level of } \\
\text { correlations }\end{array}$ \\
\hline Work/studies $0-100 \%$ & $43 \cdot 3(45 \cdot 6)$ & $53 \cdot 5(33 \cdot 0)$ & $80 \quad(34 \cdot 6)$ & $\star \star$ \\
\hline $\begin{array}{l}\text { Private transport score } 0-3 \text {; } \\
\quad 3 \text { items }\end{array}$ & $1 \cdot 4 \quad(1 \cdot 3)$ & $2 \cdot 2 \quad(1 \cdot 1)$ & $2 \cdot 1 \quad(1 \cdot 3)$ & n.s. \\
\hline $\begin{array}{l}\text { Home-making score } 0-14 \text {; } \\
\quad 7 \text { items }\end{array}$ & $0.9 \quad(1 \cdot 9)$ & $5 \cdot 0 \quad(4 \cdot 9)$ & $(4 \cdot 6)$ & $\star \star \star$ \\
\hline $\begin{array}{l}\text { Mobility in the } \\
\text { neighbourhood score } 0-4 \text {; } \\
4 \text { items }\end{array}$ & $1 \cdot 1 \quad(1 \cdot 1)$ & $2 \cdot 3 \quad(1 \cdot 6)$ & $3 \cdot 8 \quad(0 \cdot 7)$ & $\star \star \star$ \\
\hline $\begin{array}{l}\text { Physical training and sports } \\
\text { number of days/month }\end{array}$ & $3 \cdot 7 \quad(7 \cdot 5)$ & $7 \cdot 7(10 \cdot 7)$ & $4 \cdot 1 \quad(6 \cdot 4)$ & n.s \\
\hline $\begin{array}{l}\text { Social activities score } 0-6 \text {; } \\
6 \text { items }\end{array}$ & $2 \cdot 7 \quad(1 \cdot 4)$ & $2 \cdot 6 \quad(1 \cdot 9)$ & $2 \cdot 7 \quad(1 \cdot 2)$ & n.s. \\
\hline $\begin{array}{l}\text { Hobbies and interests } \\
\text { frequency }\end{array}$ & $2 \cdot 4 \quad(1 \cdot 6)$ & $2 \cdot 4 \quad(1 \cdot 3)$ & $2 \cdot 1 \quad(1 \cdot 1)$ & n.s. \\
\hline
\end{tabular}

$\star$ Pitman's permutation test.

$\star \star=\mathrm{p}<0.01$.

$\star \star \star \mathrm{p}<0.001$.

n.s. $=$ nonsignificant .

Table V Contentment with provided concrete services and equipment in 56 SCI subjects.

\begin{tabular}{|c|c|c|c|}
\hline $\begin{array}{l}\text { Service/equipment } \\
\text { received }\end{array}$ & $\begin{array}{l}\text { Recipients } \\
\text { of services/ } \\
\text { equipment }\end{array}$ & $\begin{array}{l}\text { Contented } \\
\text { with } \\
\text { services/ } \\
\text { equipment }\end{array}$ & $\begin{array}{c}\text { Discontented } \\
\text { with } \\
\text { services/ } \\
\text { equipment }\end{array}$ \\
\hline & n & $\%$ & $\%$ \\
\hline \multicolumn{4}{|l|}{ Home: } \\
\hline Home-help service & 19 & 93 & 7 \\
\hline Home adaptation & 37 & 81 & 19 \\
\hline Equipment, personal care & 36 & 89 & 11 \\
\hline Equipment, household & 13 & 96 & 4 \\
\hline \multicolumn{4}{|l|}{ Transport: } \\
\hline Transport service (taxi or special vehicle) & 39 & 95 & 5 \\
\hline Technical aids for car & 22 & 79 & 21 \\
\hline \multicolumn{4}{|l|}{ Workplace: } \\
\hline Adaptation & 16 & 100 & 0 \\
\hline Technical aids & 10 & 90 & 10 \\
\hline Post-discharge occupational therapy services & 31 & 80 & 20 \\
\hline
\end{tabular}


Table VI Relationships of community living activities to functional, psychological and sociodemographic variables and quality of life ratings in 56 SCI subjects.

\begin{tabular}{|c|c|c|c|c|c|c|c|c|c|c|}
\hline \multirow[b]{2}{*}{ Variable } & \multicolumn{2}{|c|}{ Work/studies } & \multicolumn{2}{|c|}{$\begin{array}{l}\text { Private } \\
\text { transport }\end{array}$} & \multicolumn{2}{|c|}{ Home-making } & \multicolumn{2}{|c|}{$\begin{array}{l}\text { Mobility in the } \\
\text { neighbourhood }\end{array}$} & \multicolumn{2}{|c|}{$\begin{array}{c}\text { Social } \\
\text { activities }\end{array}$} \\
\hline & $\mathbf{r}$ & p-level & $\mathrm{r}$ & p-level & $\mathrm{r}$ & p-level & $\mathrm{r}$ & p-value & $\mathbf{r}$ & p-level \\
\hline \\
\hline $\begin{array}{l}\text { (C6 tetraplegics, wheelchair-dependent } \\
\text { paraplegics, ambulant paraplegics) }\end{array}$ & $0 \cdot 38$ & $\star \star$ & $0 \cdot 21$ & n.s. & $\underline{0.69}$ & $\star \star \star$ & 0.65 & $\star \star \star$ & -0.01 & n.s. \\
\hline Self-care and mobility index & $-0 \cdot 40$ & $\star \star$ & 0.62 & $\star \star \star$ & $\overline{0.61}$ & $\star \star \star$ & 0.58 & $\star \star \star$ & $0 \cdot 20$ & n.s. \\
\hline \multicolumn{11}{|l|}{ Sickness Impact Profile } \\
\hline Overall SIP & -0.59 & $\star \star \star$ & -0.52 & $\star \star \star$ & $-0 \cdot 33$ & $\star \star$ & $-0 \cdot 48$ & $\star \star \star$ & $-0 \cdot 18$ & n.s. \\
\hline Physical dimension & -0.52 & $\star \star \star$ & $-0 \cdot 50$ & $\star \star \star$ & $-0 \cdot 49$ & $\star \star \star$ & $\overline{-0.50}$ & $\star \star \star$ & $-0 \cdot 23$ & $\star$ \\
\hline Psychosocial dimension & $-0 \cdot 35$ & $\star \star$ & $-0 \cdot 50$ & $\star \star \star$ & $-0 \cdot 06$ & n.s. & $-0 \cdot 24$ & $\star$ & $-0 \cdot 26$ & $\star$ \\
\hline \multicolumn{11}{|l|}{ Hospital Anxiety and Depression scale } \\
\hline Anxiety dimension & $-0 \cdot 04$ & n.s. & $-0 \cdot 26$ & $\star$ & -0.27 & n.s. & -0.09 & n.s. & $-0 \cdot 15$ & n.s. \\
\hline Depression dimension & $-0 \cdot 36$ & $\star \star$ & $-0 \cdot 50$ & $\star \star \star$ & $-0 \cdot 28$ & $\star$ & $-0 \cdot 26$ & $\star$ & $\underline{-0.36}$ & $\star \star$ \\
\hline \multicolumn{11}{|l|}{ Mood Adjective Check List } \\
\hline Pleasantness/unpleasantness & $0 \cdot 08$ & n.s. & $0 \cdot 21$ & n.s. & $-0 \cdot 02$ & n.s. & 0.06 & n.s. & $0 \cdot 37$ & $\star \star$ \\
\hline Activation/deactivation & $0 \cdot 23$ & n.s. & $0 \cdot 33$ & $\star$ & $0 \cdot 08$ & n.s. & $0 \cdot 16$ & n.s. & $0 \cdot 29$ & $\star$ \\
\hline Calmness/tension & -0.02 & n.s. & $0 \cdot 15$ & n.s. & $-0 \cdot 19$ & n.s. & -0.06 & n.s. & $0 \cdot 24$ & n.s. \\
\hline Quality of Life rating & $0 \cdot 31$ & $\star$ & $\underline{0.53}$ & $\star \star \star$ & $0 \cdot 41$ & $\star \star$ & 0.32 & $\star$ & $\underline{0.39}$ & $\star \star$ \\
\hline Age & $-0 \cdot 25$ & $\star$ & $-\overline{0 \cdot 31}$ & $\star \star$ & -0.46 & $\star \star \star$ & -0.31 & $\star \star$ & $-\overline{0.34}$ & $\star \star$ \\
\hline Age at injury & $-0 \cdot 30$ & ^ & $-0 \cdot 36$ & $\star \star$ & -0.43 & $\star \star \star$ & $-0 \cdot 30$ & $\star \star$ & $-0 \cdot 40$ & $\star \star \star$ \\
\hline Time since injury & $0 \cdot 15$ & n.s. & $0 \cdot 21$ & n.s. & -0.04 & n.s. & -0.01 & n.s. & $0 \cdot 25$ & n.s. \\
\hline Sex & $-0 \cdot 12$ & n.s. & $-0 \cdot 21$ & n.s. & $0 \cdot 09$ & n.s. & $-0 \cdot 10$ & n.s. & $-0 \cdot 15$ & n.s. \\
\hline Living arrangements & $0 \cdot 19$ & n.s. & 0.05 & n.s. & $-0 \cdot 13$ & n.s. & $-0 \cdot 16$ & n.s. & $-0 \cdot 18$ & n.s. \\
\hline Education & $0 \cdot 24$ & n.s. & $0 \cdot 16$ & n.s. & -0.07 & n.s. & $0 \cdot 005$ & n.s. & $0 \cdot 28$ & $\star$ \\
\hline
\end{tabular}

$\mathrm{r}=$ Pearson's correlation coefficient.

$\star=\mathrm{p}<0.05$.

$\star \star=\mathrm{p}<0.01$ Pitman's permutation test.

$\star \star \star \mathrm{p}<0.001$

n.s. $=$ nonsignificant.

Underlined values denote the strongest independent predictors in each activity category, according to nonparametric partial correlation (Mantel's test). 


\section{Work or education}

Six subjects had retired before injury. Out of the remaining 50 subjects, 24 were engaged in gainful employment and 16 in education. Half of those who were employed had received complementary vocational training before work return. Twenty-two persons had full-time employment or education. All but 2 subjects were content or very content with their work or studies.

As shown in Table VI, the level of engagement in gainful employment/education was associated both with physical function (severity of disability, dependence for self-care and mobility, SIP physical dimension) and with emotional status (HAD, SIP psychosocial dimension) and QL.

Thirty-five per cent of the total variance of work or education levels was explained by one independent variable, overall SIP (the less general dysfunction after injury, the better).

\section{Private transport}

Thirty-four subjects (61\%) were driving their own car. Being able to drive a car and to manage independent car transfers was strongly associated with mental wellbeing (HAD, $\mathrm{p}<0.001$; SIP psychosocial dimension, $\mathrm{p}<0.001)$ and with high $\mathrm{QL}(\mathrm{p}<0.001)$. Car-driving was not correlated to severity of disability per se but closely associated with independence in self-care and mobility $(p<0.001)$ and with younger age and younger age at injury (see Table VI).

Three variables explained $54 \%$ of the total variance in private transport outcomes: SIP psychosocial dimension, independence in self-care and mobility and perception of overall QL.

\section{Home-making}

Subjects in the C6 tetraplegic group very rarely performed these tasks (kitchen chores, washing, and cleaning). Wheelchair-dependent paraplegics participated in on average 3 of the 7 suggested activities and ambulant paraplegics in on average 6 . Subjects who needed assistance with home-making usually obtained it from homehelps and not from relatives.

Level of engagement in home-making was mainly correlated to physical function (severity of disability $\mathrm{p}<0.001$; dependence for self-care and mobility $\mathrm{p}<0.001$; SIP physical dimension $\mathrm{p}<0.001$ ).

Higher scores of this index were also correlated to younger age and younger age at injury $(\mathrm{p}<0.001)$ and higher quality of life $(\mathrm{p}<0.01)$. Living arrangements (living alone, living with spouse or cohabitant, living with parents) were not correlated to home-making (Table VI).

Fifty-one per cent of the total variance in home-making could be explained by severity of disability and dependence for self-care and mobility.

\section{Mobility in the neighbourhood}

The majority of the subjects $(82 \%)$ were able to drive the wheelchair or walk in their immediate surroundings. About half of the wheelchair dependent subjects 
had an accessible post office, shops and bank in their neighbourhood. However, very few tetraplegics and only half of the wheelchair dependent paraplegics made use of these facilities.

Involvement in these activities was highly correlated to physical variables (severity of disability $\mathrm{p}<0.001$; dependence for self-care and mobility $\mathrm{p}<0.001$; SIP physical dimension $\mathrm{p}<0.001)$ and moderately correlated to younger age and younger age at injury (Table VI).

QL and mental well-being (HAD) showed a weak but significant correlation to this category of activity (Table VI).

Three of the independent variables accounted for $49 \%$ of the total variance in neighbourhood mobility: severity of disability, level of dependence for self-care and mobility and total impact of the injury as measured by overall SIP.

\section{Physical training and sports}

Twenty-two subjects (39\%) were engaged in regular physical exercise or sports. The quantity of training varied between 4 and 30 days a month, with a median of 12 days. Archery and road-racing were most frequently reported by the C6 tetraplegics, swimming, basketball and archery by the wheelchair-dependent paraplegics and weight-lifting by the ambulant paraplegics. Sufficient training by everday activities, lack of interest, lack of time and fatigue were reported reasons for not engaging in regular physical exercise and sports. Only 3 subjects said that absence of training facilities was the reason.

Engagement in physical training and sports was not significantly correlated to any of the independent variables (results not shown in Table).

\section{Social and recreational activities}

Thirty subjects (54\%) had taken part in at least 3 out of 6 suggested social activities during the previous month and 12 subjects $(21 \%)$ in less than 2 .

High social activity was associated with good QL $(\mathrm{p}<0.01)$, lack of depression $($ HAD $p<0.01)$ and high level of mood MACL pleasantness $p<0.01)$. Young age and young age at injury were positively correlated to social activity $(\mathrm{p}<0.01$ and $\mathrm{p}<0.001$ respectively). Neither the severity of disability nor the level of dependence for self-care and mobility was correlated to social interaction (Table VI).

Twenty-two per cent of the total variance of social activity level was explained by age at injury (the younger the better), mental well-being (HAD) and perceived QL.

The majority of the subjects $(71 \%)$ reported that they had 2 or more hobbies or specific leisure activities apart from their usual social contact and very few (3\%) that they had none at all. Sixteen subjects (29\%) reported that they had maintained their earlier interests and $15(27 \%)$ that they had been able to adapt preinjury activities to the disability. Nineteen persons (34\%) had taken up new leisure activities after injury. Most commonly reported new interests were sports, books, music and participation in formal organisations.

Quantity of leisure activities showed no correlation to any of the measured independent variables. 


\section{Discussion}

\section{Methodological considerations}

The 56 study subjects comprised all of a consecutive series that belonged to 3 defined functional subgroups. This selection of subjects made it possible to study the impact of specific functional limitations (degree of impaired arm and hand function and/or wheelchair dependency) on activity levels. Unlike SCI materials reported from other Western societies, they did not seem to constitute a negative socioeconomic selection of the total population. We think the difference is due to how our society is organised: few people fully earn their living before the age of 20 and social misery is very rare, not counting the most severe antisocial or psychiatric deviants. Society's ambition for the handicapped is to offer proper living and work facilities irrespective of the level of productivity. Furthermore, a few study subjects active in education or vocational training may ultimately fail and join the small group of disability pension cases.

The SCI specific indexes, not yet validated beyond their development, called for cautious analyses. They were developed according to psychometric standards and used in combination with well-established generic measures. We think that they yielded relevant information for the clinician.

The ultimate way to evaluate a social support system, such as the one utilised by our subjects, is to measure its effects as perceived by the recipients. Response set bias, e.g. social desirability, was considered in this study; we applied the technique of asking several specific questions and avoided any global rating. The subjects' assessments concerned services provided by agencies outside the Spinal Unit. Almost all perceived our society's provisions in the health care and social security systems as patients' minimum rights; SCI subjects are taught to demand these.

\section{Significant findings of the study}

The impact of the severity of disability was especially evident in two activity areas; home and kitchen management and mobility in the neighbourhood. The low rate of participation in these activities among the wheelchair-dependent subjects, the C6 tetraplegics in particular, has several explanations. Obviously, some of these tasks require a certain amount of motor and sensory function, in order not to consume too much time and energy. Furthermore, wheelchair-dependent subjects are likely to be more limited by inaccessible housing or outdoor architectural barriers often associated with these activities. Some persons may therefore prefer to obtain assistance with home-making, shopping etc in order to be able to spend more time on other activities, or choose to be more independent in self-care skills. This suggestion is supported by the fact that our wheelchair-dependent subjects were considerably more independent in self-care activities than in home-making tasks. In contrast, engagements in social and recreational activities, physical training and private transport were not restricted by more severe disability. Many of the subjects, including the tetraplegics, had succeeded in finding new interests and hobbies or adapting preinjury leisure activities to the disability. Moreover, access to transport, necessary for an active leisure time, was well provided for in this group of subjects, none of whom lived in an institution. 
Engagement in social activity and ability to drive one's own car correlated closely to levels of mental well-being and to perceived overall quality of life, these factors clearly outweighing the impact of physical dysfunction. Obviously, the direction of this association cannot be determined; persons free of depression and highly satisifed with their lives are more likely to participate in these activities and increased activity levels may also have a positive influence on mental well-being and quality of life.

Age and age at injury were negatively correlated to activity levels in all areas, this being most evident in social activities. This finding may simply reflect the fact that older persons are more vulnerable to major changes in life, have less energy and are less motivated to find new goals and interests. However, one cannot exclude the possibility that elderly members of the society are less well provided for in both vocational and other activities.

Accessibility of the environment greatly raises a person's ability to resume a productive life in the community (Trieschmann, 1980; De Jong, 1984). Access to transport and home-help services, suitable housing and technical aids were the main environmental factors investigated in this study. The finding that only a few subjects reported discontentment or unmet needs in these respects (Table V) confirmed that some important limitations of the environment had been satisfactorily dealt with. This may explain the fact that these environmental factors were not associated with activity levels.

Thus, despite considerable group differences in level of physical function, the majority of the subjects $(80 \%)$ were gainfully employed or engaged in studies and, in general, had an active leisure time. They also reported normal or close to normal mood states and QL perceptions, with little difference between the 13 functional groups.

We conclude that, with extensive society support and stimulation, the majority of persons with SCI can lead a satisfying and productive life in the community.

\section{Acknowledgements}

We thank NG Pehrson, systems analyst, for data processing and L Claesson, OT and M Flymar, OT for collection and control of data. The investigation was supported by grants from the Swedish Council for Planning and Coordination of Research (No. 880264:3), the Ministry of Health and Social AffairsCommission for Social Research (No. E88/11), the Norrbacka-Eugenia Foundation and the Greta and Einar Asker Foundation.

\section{References}

Bergner M, Bobbit RA, Carter WB, Gilson BS 1981 The Sickness Impact Profile: development and final revision of a health status measure. Medical Care 19:787-805.

BRADLEY JW 1968 Distribution-free statistical tests. Prentice-Hall, London, pp. 68-86.

DEJong G, Branch LG, CoRCoRAN PJ 1984 Independent living outcomes in spinal cord injury: Multivariate analyses. Archives of Physical Medicine and Rehabilitation 65:66-73.

GoldBerg RT, Bernad M, Granger CV 1980 Vocational status: Prediction by Barthel index and PULSES profile. Archives of Physical Medicine and Rehabilitation 61:580-583.

LundQvist C, Siösteen A, Blomstrand C, Lind B, Sullivan M 1990 Spinal cord injuries: Part I: Clinical, functional, and emotional status (Spine. In press).

MacDonald MR, NiElson WR, CAMERON MGP 1987 Depression and activity patterns of spinal cord injured persons living in the community. Archives of Physical Medicine and Rehabilitation 68: 339-343.

MCDowell I, Newell C 1987 Measuring health. Oxford University Press, Oxford, pp 18-19. 
MANTEL N 1963 Chi-square test with one degree of freedom: extensions of the Mantel-Haenszel procedure. 7 Am Stat Assoc 58:690-700.

NunNally NC 1978 Psychometric theory. 2nd ed. McGraw-Hill, New York.

SJÖBERG L, SvensSON E, PERSSON LO 1979 The measurement of mood. Scandinavian fournal of Psychology 20:1-18.

Trieschmann RB 1980 Spinal cord injuries. Psychological, social and vocational adjustment. Pergamon Press Inc., London, New York.

Zigmond AS, Snaith RP 1983 The Hospital Anxiety and Depression Scale. Acta Psychiatrica Scandinavica 67:361-370. 